\title{
Optimization Algorithm in Traditional Card Game Rummy 21
}

\author{
A. A. K. Oka Sudana \\ Department of Information \\ Technology, Udayana \\ University, Bali, Indonesia
}

\author{
I. Gd. Km. Puja Aditya \\ Department of Information \\ Technology, Udayana \\ University, Bali, Indonesia
}

\author{
I. Pt. Agus Eka Pratama \\ Department of Information \\ Technology, Udayana \\ University, Bali, Indonesia
}

\begin{abstract}
Everyone will want to get the best in life, maximize or optimize what owned to get something better. The best results are affected by the decision optimally taking into account all the constraints. This is became the basis for new breakthroughs in the game by developing the science of artificial intelligence (AI). How computer game can make the best decision by looking at the existing constraints or limitations. Algorithm optimization has fully supported the decision, using the object Balinese traditional card game Rummy 21. The main concept of the game Rummy 21 is to calculate the value of the card. Player gets a value of about 21, and not more than 21. Cards exceeds the number 21 does not qualify or fall. Decision-making in the game Rummy 21 is making the decision to add a card or survive on the value of the card now. Implementation of AI in this game is devoted to the single player game. The purpose of this study was to produce a game with AI features that can think like humans in solving problems while preserving the traditional game using the technology of mobile gaming.
\end{abstract}

\section{General Terms}

Implementation AI, Optimization Problem, Decision-making, Single Player Games, Balinese Traditional Topic.

\section{Keywords}

Card Games, Artificial Intelligence (AI), Optimization Algorithm, Single Player.

\section{INTRODUCTION}

The Balinese traditional game is a game the people Bali who intended as a means of entertainment [9]. Various kind of game traditional in Bali not be exhausted to talk about, one of which is the card game Traditional Bali. Card game is a game of simple use the card as a medium game. Game Rummy 21 is one of a game a popular in Balinese community. Game Rummy 21 played three to eight people, with this type of card games count. Player will count number of cards according to the number of approaching or same with 21 , according to purpose or goal game Rummy 21. Cards exceeded the number of 21 is going did not qualify [8].

As the technological development in the field of Artificial Intelligence (AI), making the card game can be designed Single Player. Artificial intelligence (AI) will reduce the problem of shortage of opponents to play and to hone the user logic in developing the ability to play.

Optimal decision making, namely, how to solve a problem can be solved with the best steps [11]. Optimization algorithms are applied to the development of AI in the card game Rummy 21 is to optimize the steps to be taken to obtain optimal results. Optimization decisions will shape the solution step by step with their choices or possibilities to consider.
Therefore, at every step or opportunities need to be made the best decision in determining the choice. Decisions have been taken on a step can't be changed on the next step [10].

The development of this type of game has come to the manufacture of artificial intelligence (AI) as a technique used in the game to produce the illusion or artificial intelligence for a character that is not a player. In the field of gaming, AI would act as the main opponent without the help of other players will be moved in accordance with the algorithms used. "Capsa Banting" is a card game which is quite popular among adolescents and adults in Indonesia. The design of this game used the minimax algorithm in decision step. Designed to make the computer can take steps to the maximum value and can see the next steps to be done players [4].

AI development has attracted public attention by the media used as entertainment in the form of a game. AI in a game can be a challenge in completing a game or an opponent to play. Game card "Blok Bakar" is a Balinese traditional card game. Game "Blok Bakar" using randomization of card techniques combine the two methods of randomization Linear Congruent Generators (LCG) and Linear Feedback Shift Register (LFSR) to obtain a random card and minimize the appearance of the same card. The application result of a combination these methods, capable of equalizing the percentage level of victory and defeat AI computer [1].

Traditional card game Rummy 21 must be preserved. The traditional game Rummy 21 can be conserved by using the technology of mobile gaming. Android-based mobile gaming applications can be a medium for playing a card game that can be accessed via smartphone. Development of the technology of artificial intelligence (AI) makes it possible to design a game Rummy 21 with the support of the single-player game. The results of this study can apply rules Rummy 21 to the base of mobile game on android with Artificial Intelligence (AI) feature. This application can be used as entertainment for card games and retain the traditional game Bali so as not to be forgotten.

\section{LITERATURE REVIEW}

\subsection{Artificial Intelligence}

An artificial intelligence (AI) is a region research, application and instruction associated with computer programming to do the smart things in the sight of human [5] [6]. With the advent of the artificial intelligence in the era of rapid technology can be classified as follows [3] [5].

1. Expert system, computer as a means of storing knowledge experts so that the computer has skill solve problems by imitating skills owned experts [3] [5]. 
2. The Natural Language, player can be able to communicate with computer use Colloquially, English, Indonesian language, and etc. [3] [5].

3. Speech Recognition (Speech Recognition), humans can communicate with the computer using the voice [5].

4. Robotics \& Sensor Systems [3] [5].

5. Computer vision, the interpretation of the objects a picture or looked through the computer [5].

6. Intelligent computer-aided instruction, computer can be used as the coaches are can exercise \& teaching [5].

7. Soft computing, is a system with expertise as people on a given domain, capable of adapting and learn to work more better if evidence for changes environment. Soft computing exploit the sanction to inaccuracy, uncertainty, and the truth partial to can be completed and controlled easily to fit to reality [5].

\subsection{Algorithm Optimization}

The Optimization algorithms are steps to resolve the problem without any criteria that declares an element is a solution, but only the functions that describe objectively whether or not given configuration or finding optimal solutions and the best with the possibilities [8] [10].

Based on the method of operation, classification or kind of optimization algorithm is divided into two, is deterministic and probabilistic algorithms [2] [11].

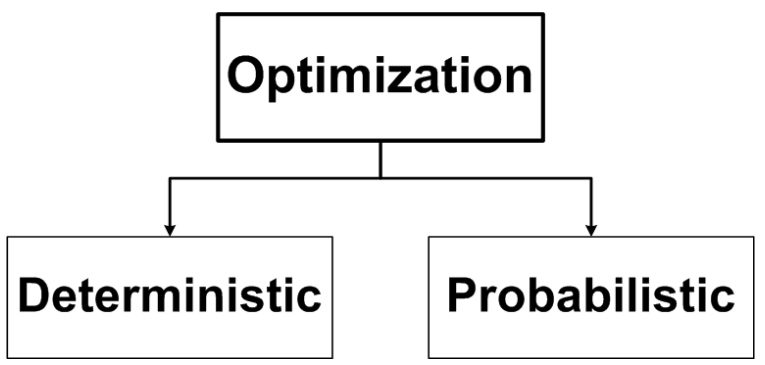

Fig 1: Classification Algorithm Optimization

The fundamental differences between the two groups were at each step of execution (Figure 1). Deterministic optimization of the algorithm, there is only one way to be processed, if there is no way the algorithm is considered complete. This optimization has always resulted in a solution that is fixed for given input. Deterministic algorithms typically used for problems whose solution space is not too big. Probabilistic optimization algorithm used to solve the problem space to the solution space is very large, even infinite. Probabilistic algorithms try to find the best solution, to do repeatedly without exceeding the time limit specified. The best solution is not necessarily the most optimal, but it is already unacceptable [2] [11].

\subsection{Game Description}

Rummy 21 is playing a card games who add up the value of cards. The main concepts game Rummy 21 devoted to the players have to get the number of card worth 21 . The player who does not given a value of 21 , can be kept moving closer to the number of 21 to continue to add a card with maximum 6 of cards in the hand. But, if the value is exceeding 21 players did not qualify and lose points [7] [12].

\subsubsection{Object of the Game}

The standard playing cards using two packs of used (104 cards) without cards worth 10 (will become 96 cards). In playing game Rummy 21 ace worth 1 or 11 . Cards picture worth 10 and others like cards 1 to 9 worth normal. Every participants are trying to get an approaching 21, without beyond 21 . The following are table value a card game Rummy 21 [7] [12].

Table 1: Cards Value of Rummy 21

\begin{tabular}{|c|c|}
\hline Card & Value \\
\hline Ace & 1 or 11 \\
\hline King & 10 \\
\hline Queen & 10 \\
\hline Jack & 10 \\
\hline Two & 2 \\
\hline Three & 3 \\
\hline Four & 4 \\
\hline Five & 5 \\
\hline Six & 6 \\
\hline Seven & 7 \\
\hline Eight & 8 \\
\hline Nine & 9 \\
\hline
\end{tabular}

\subsubsection{Rule of Game}

At the beginning of the game, the player gets two cards in hand. The first condition when two cards of player card is an ace and a picture card value 21 , this is the objective of the game by the name of "Ngerusak", but this condition is defeated when two cards of player is an ace doubles (ace and ace), this is a card angel with the name "Ngeliper ". If any player is not in condition "Ngerusak" or "Ngeliper" game continued with "Ngadu" (comparing the value of the card). In the state of "Ngadu", the player adds a card with a maximum capture as many as four cards to get the value of approximately 21 . When one player collects six cards in hand (maximize capture card) with values close to 21 and not more than 21, the name is "Ngertu" [7].

\subsubsection{Ngerusak (21)}

Ngerusak is a condition when the players got an ace and a "card ten" (cards picture King / Queen / Jack). The game will automatically stop when one or more players scored 21 or Ngerusak [7].

\subsubsection{Ngeliper (Double Ace)}

Ngeliper is a condition when the players got an ace and ace (double ace). Ngeliper beat Ngerusak or 21 defeated double ace [7].

\subsubsection{Ngadu (Comparing the Value of the Card)} Ngadu is a condition in which not all players can Ngerusak or Ngeliper. On the cards is done by adding a card with a maximum of six cards with a card approaching 21. Players who exceed the 21 disqualified [7].

\subsubsection{Ngertu}

Ngertu is a condition when one player to collect a maximum of cards (six cards), and the total number of cards is not more than 21 or equal to 21 . Ngertu can beat all grades opponent. Although the value of the opponent is the maximum value and the value is smaller Ngertu [7]. 


\section{APPLICATION DEVELOPMENT}

\subsection{Designing of Game}

A general overview Rummy 21 illustrates a flow of the game can be seen in Figure 2.

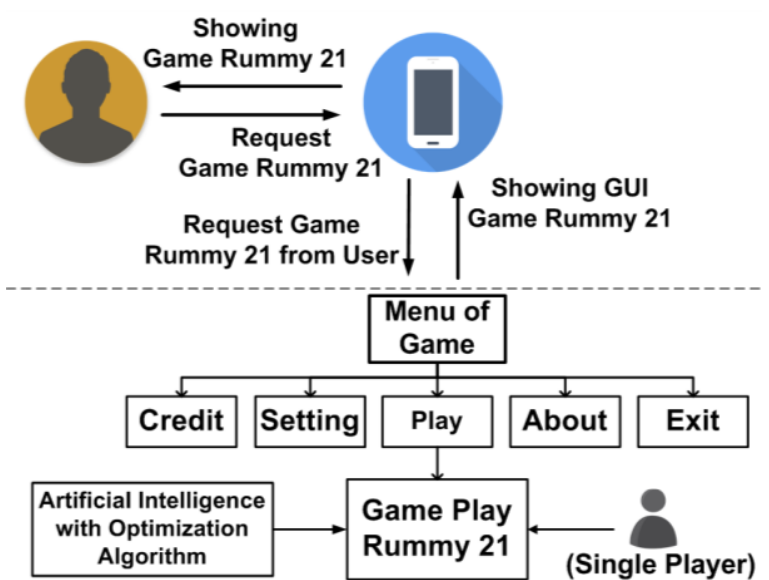

Fig 2: General Picture of Game Rummy 21

Game Rummy 21 was designed based on smartphone. Figure 2 is a general overview of the game rummy 21 with the interaction between the user and the system via the media smartphone. Game Rummy 21 is wrapped by smartphone that is accessible by the user. Users request the game and the smartphone will display the game menu. The system processes the game is play when the users select "Play". When entering into game play, users will play Rummy 21 and combined with Artificial Intelligence to support the opponent (computer) user and single player games.

\subsection{Flowchart}

Understanding more detailed description by the flowchart will be explained with a data stream in the game Rummy 21 .

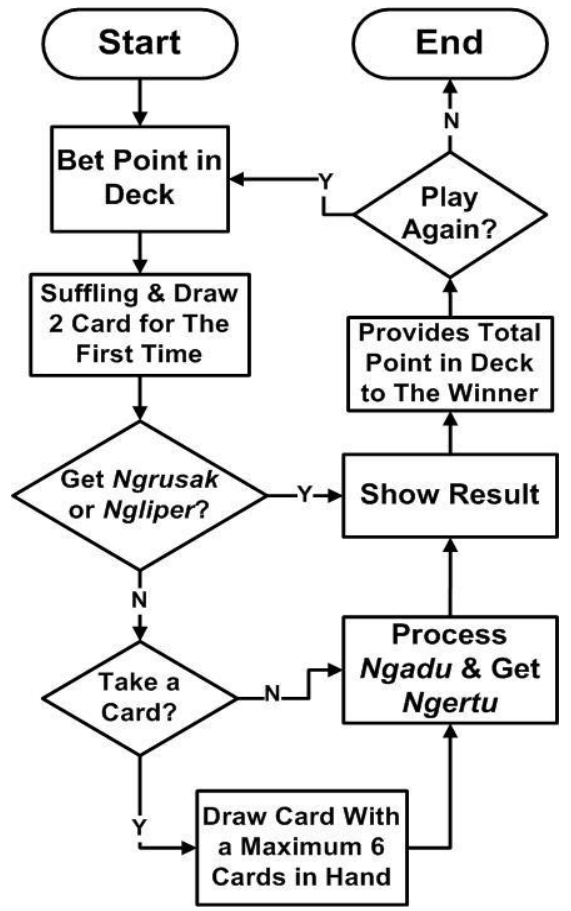

Fig 3: Flowchart of the Process Game Rummy 21
The flow of the game begins when a player entrance and select menu for the play. First to play Game Rummy 21, player must be fill name and chose the avatar in the beginning of the game. Then setting the game and choose a position to play and start the game. Two cards are dealt and the condition Ngerusak or Ngeliper will be checked by the system in the beginning of the game. When it is not any player get, were then followed by Ngadu (comparing the value of the card). Player has the opportunity to take a maximum six of cards in the hand to find the total points closer to 21 . The process of Ngertu enables the player to win a game by taking maximize the use of cards with the risk of bankruptcy (a bust) increased. But, if player gets Ngertu, then the players can end of the game and defeated all the value of the card player to the other when to show their cards.

The general description of game has an important role in providing information and goal in designing game Rummy 21 . The process is visible of outline in the game explained the flow of the game and the rules of the card game Rummy 21 to the user.

\subsection{Optimization Algorithm in AI}

Usage Optimization Algorithm in AI to optimize decision with all the possibilities that exist or the obstacles that will affect the solution, according to the candidate. The solution is expected to be affected by the problem of interest. On Rummy 21 there are elements that influence the decision (solution) optimization, namely:

1. Interest, find the value on the card close to or equal to 21 .

2. Candidates, cards that have not been drawn.

3. Solution, solving problems containing the candidates elected.

4. Constraints, restrictions in the Rummy 21, namely:

a. Minimal value of the card is 17 .

b. Looking for value with no more than 21 cards with restrictions add as much as 4 cards.

c. Taking the card to match the rest of the number of players.

5. Selection, the decision to take the card or survive according to the conditions.

6. Eligibility, check whether a candidate's decision together with a set of solutions that have been formed not violate constraints.

AI systems work on the Game Card Rummy 21, when a player decides to add or survive on the value of cards collected to approach 21 without violating the constraints are quite large (more than 21). The player must take a card when the value is less than 17. Computer can choose to "Survive" when the card value between 17 and 21 . The computer will select "Add" to take out the card when the card value is less than 17 or have the opportunity to approach a value of 21 . When players take a card or retain cards, decision-making is influenced by the number of players who played with a minimum limit of the value of cards in hand as a constraint.

\subsection{Result of Optimization}

AI system work on the Game Card Rummy 21, when a player decides to add or survive on the value of cards collected to approach 21 without violating the constraints are quite large (more than 21). The player must take a card when the value is less than 17. Computer can choose to "Survive" when the card value between 17 and 21 . The computer will select "Add" to take out the card when the card value is less than 17 or have the opportunity to approach a value of 21 . When players take a card or retain cards, decision-making is influenced by the 
number of players who played with a minimum limit of the value of cards in hand as a constraint.

Solutions that can be generated by made level with the level in AI vulnerable boundary value. When a player chooses to add to the card, the AI will check the level of the player according the condition of the rest of the players.

1. Level $1=$ Vulnerable between $17-21$

2. $\mathbf{L e v e l} \mathbf{2}=$ Vulnerable between $19-21$

Optimization results are used in the process Ngadu rules, when decision-making of the player chooses to take the card or retain cards to approach the value of 21 , based on the current level.

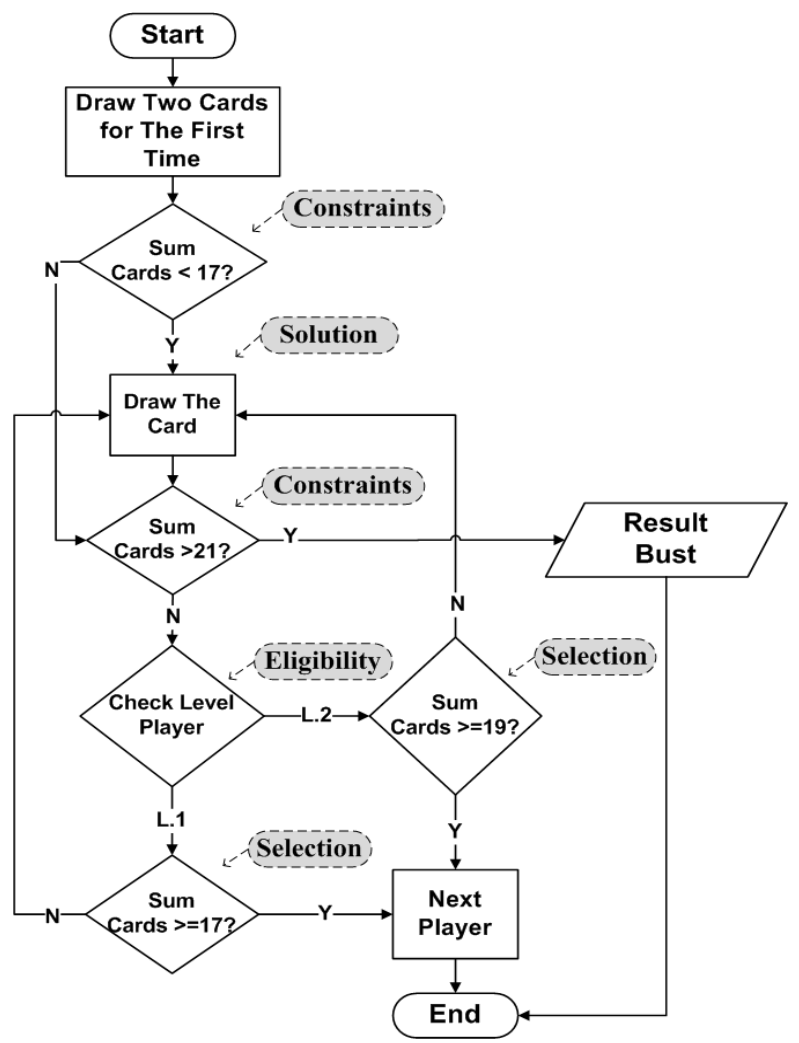

Fig 4: Flowchart of the Result Optimized AI

Flowchart in Figure 4 show the performance of AI using optimization measures, which the computer AI will check the feasibility of the cards after choosing to add to the card. Eligibility is determined by the number of remaining players still playing. Computer AI is at level 2, when the remaining amount of players more than half of the number of players $(>50 \%)$. Computer $\mathrm{AI}$ is at level 1 , when the number of remaining players is less than or equal to half of the number of players $(\leq 50 \%)$. The conclusion of the performance of computer AI, the more the rest of the players who still come into play in the process $N g a d u$ or penalty card, then the addition of cards that do will be higher (optimize) without violating constraints. However, the less the rest of the players are playing, the computer AI will choose to survive with the limit values specified (safety position).

\section{RESULT AND DISCUSSION}

\subsection{Implementation AI}

Implementation AI for game Rummy 21, when the player add to the card at every step if the possibility of the presence of the card in a candidate (approaching 21) so it does not violate constraints large enough (over 21).

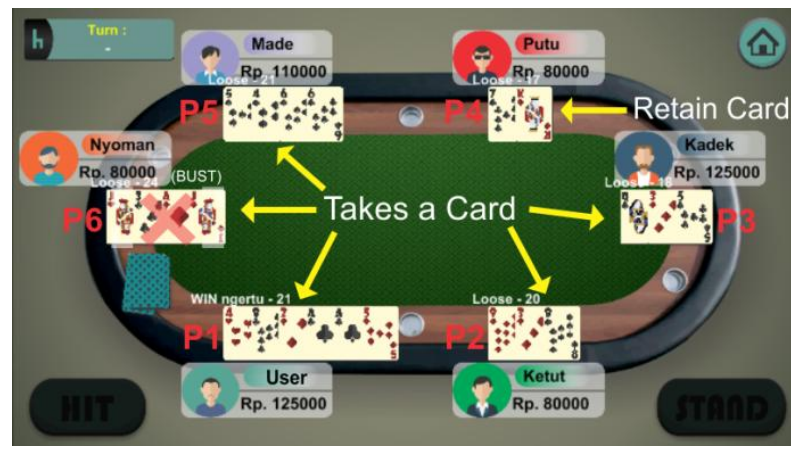

Fig 5: Decision to Take or Retain a Card

Figure 5 illustrate the implementation of the AI when a player chose to take out the card or survive on the value of the card that has been obtained. "P1", "P2", "P3", "P5", "P6" chose to add the card because the number of card values less than 17 or have a chance to approach the value 21 and "P4" chose to survive because it has to be in vulnerable 17 between 21 .

The player will only pay attention to the card that is now owned and cards may still are drawn by the player and not pay attention to the card owned by another player. By using this strategy at every step or opportunity, expected number of players gain optimum value card.

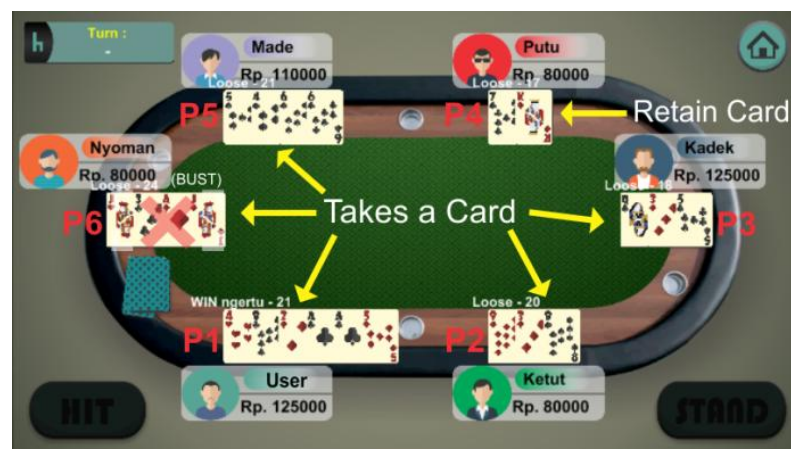

Fig 6: Result When Player Take or Retain a Card

Figure 6 show the final result of the game, the winner is "P1" to the maximum value after doing $N g a d u$ and in accordance with the rules of the game the name is "Ngertu". Values exceeding 21 will be disqualified, like the "P6" with a value exceeding 21 cards.

Ngertu can be done by collecting six cards in hand with a value of less than or close to 21. Computer have the opportunity Ngertu with a card reading in hand to enable get a score approaching 21 , and automatically add the card when have a chance Ngertu. Before process Ngertu is Ngadu. $N g a d u$ is comparing the total value of cards that have been collected to determine the winner. When the player have six cards in hand and amounted to approach the 21 , then the player will directly win with the name of Ngertu. Ngertu defeat all value players even though value another player greater than the Ngertu.

Other rules of game Rummy 21 is Ngerusak and Ngeliper. In rule of Ngerusak or Ngeliper will automatically win the game. 


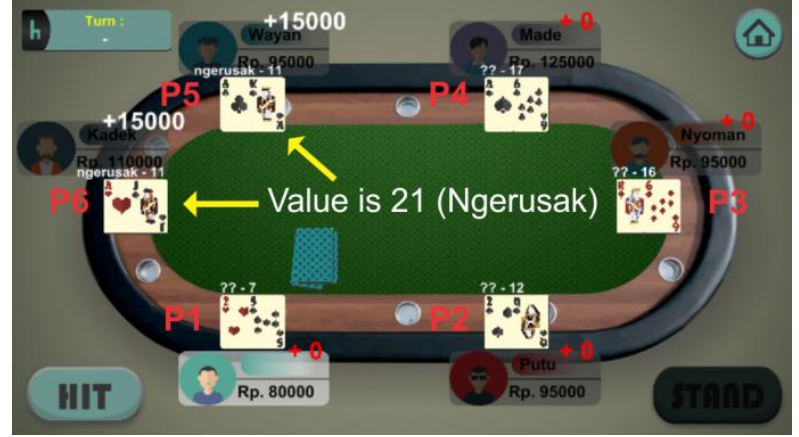

Fig 7: Condition When Players Gets Value 21 (Ngerusak)

Ngerusak is a condition in which the player gets value of the cards is 21 . The game will be immediately stopped when one or more players scored 21 or Ngerusak. Figure 7 showing the condition of Ngerusak, when "P5" and "P6" gets value is 21 to win the game automatically.

Ngeliper is the condition player gets an ace double. Ngeliper defeat Ngerusak condition. Figure 8 showed a condition Ngeliper.

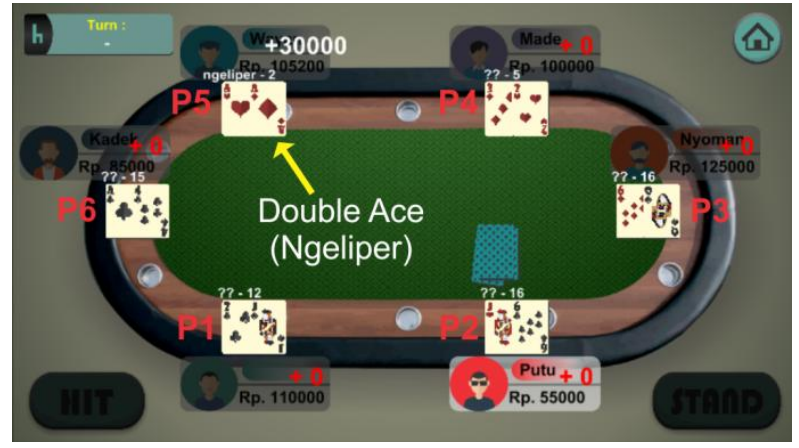

Fig 8: Condition When Player Gets Double Ace (Ngeliper)

When the player get double ace, then that player is gets Ngeliper. Ngeliper defeat Ngerusak, so when in the game one of the players get Ngerusak and another player get Ngeliper, then the player who obtain Ngeliper win the game. Figure 8 shows "P5" get a double ace and become a winner.

\subsection{Result of Application Test}

\subsubsection{Testing of Program}

Testing has been done by comparing the results as the game progresses. The comparison result is decided when the game without optimization algorithm and when the optimization algorithm used. Testing took the opportunity to sample 50 chance of $\mathrm{Ngadu}$ conditions (compare the value of the cards) with the possibility of AI players get a bust. Tested use the six players who played with one player user and five players AI.

\begin{tabular}{|c|c|c|c|c|c|c|c|}
\hline \multirow[b]{2}{*}{$\begin{array}{c}\text { Player } \\
\text { (AI) }\end{array}$} & \multicolumn{4}{|c|}{ Quantity } & \multicolumn{3}{|c|}{ Percentage } \\
\hline & $\begin{array}{c}\text { Chance } \\
\text { of } \mathrm{Ngadu}\end{array}$ & Win & Lose & Bust & Win & Lose & Bust \\
\hline PC1 & 50 & 10 & 28 & 12 & $20 \%$ & $56 \%$ & $24 \%$ \\
\hline PC2 & 50 & 11 & 23 & 16 & $22 \%$ & $46 \%$ & $32 \%$ \\
\hline PC3 & 50 & 13 & 22 & 15 & $26 \%$ & $44 \%$ & $30 \%$ \\
\hline PC4 & 50 & 11 & 19 & 20 & $22 \%$ & $38 \%$ & $40 \%$ \\
\hline PC5 & 50 & 12 & 21 & 17 & $24 \%$ & $42 \%$ & $34 \%$ \\
\hline \multicolumn{2}{|c|}{ Total } & 57 & 113 & 80 & $23 \%$ & $45 \%$ & $32 \%$ \\
\hline
\end{tabular}

Fig 9: Result of Tested without Optimization Algorithm

Figure 9 is a table to show the results of tested without optimization algorithm, the percentage of winning and losing of each player AI in 50 chance of $\mathrm{Ngadu}$. The results obtained for the total percentage of winning is $23 \%$, losing is $45 \%$ and the bust is $32 \%$.

\begin{tabular}{|c|c|c|c|c|c|c|c|}
\hline \multirow{2}{*}{$\begin{array}{c}\text { Player } \\
\text { (AI) }\end{array}$} & \multicolumn{4}{|c|}{ Quantity } & \multicolumn{3}{|c|}{ Percentage } \\
\cline { 2 - 8 } & $\begin{array}{c}\text { Chance } \mathbf{N g a d u} \\
\text { PC1 }\end{array}$ & Win & Lose & Bust & Win & Lose & Bust \\
\hline PC2 & 50 & 19 & 22 & 9 & $38 \%$ & $44 \%$ & $18 \%$ \\
\hline PC3 & 50 & 23 & 14 & 12 & $42 \%$ & $34 \%$ & $24 \%$ \\
\hline PC4 & 50 & 21 & 13 & 16 & $42 \%$ & $26 \%$ & $32 \%$ \\
\hline PC5 & 50 & 18 & 20 & 12 & $36 \%$ & $40 \%$ & $24 \%$ \\
\hline \multicolumn{2}{|c|}{ Total } & $\mathbf{5 7}$ & $\mathbf{1 1 3}$ & $\mathbf{8 0}$ & $\mathbf{4 1 \%}$ & $\mathbf{3 4 \%}$ & $\mathbf{2 5 \%}$ \\
\hline
\end{tabular}

\section{Fig 10: Result of Tested with Optimization Algorithm}

Figure 10 is table to show the results of tested with optimization algorithm and the results obtained for the total percentage of winning is $41 \%$, losing is $34 \%$ and the bust is $25 \%$.

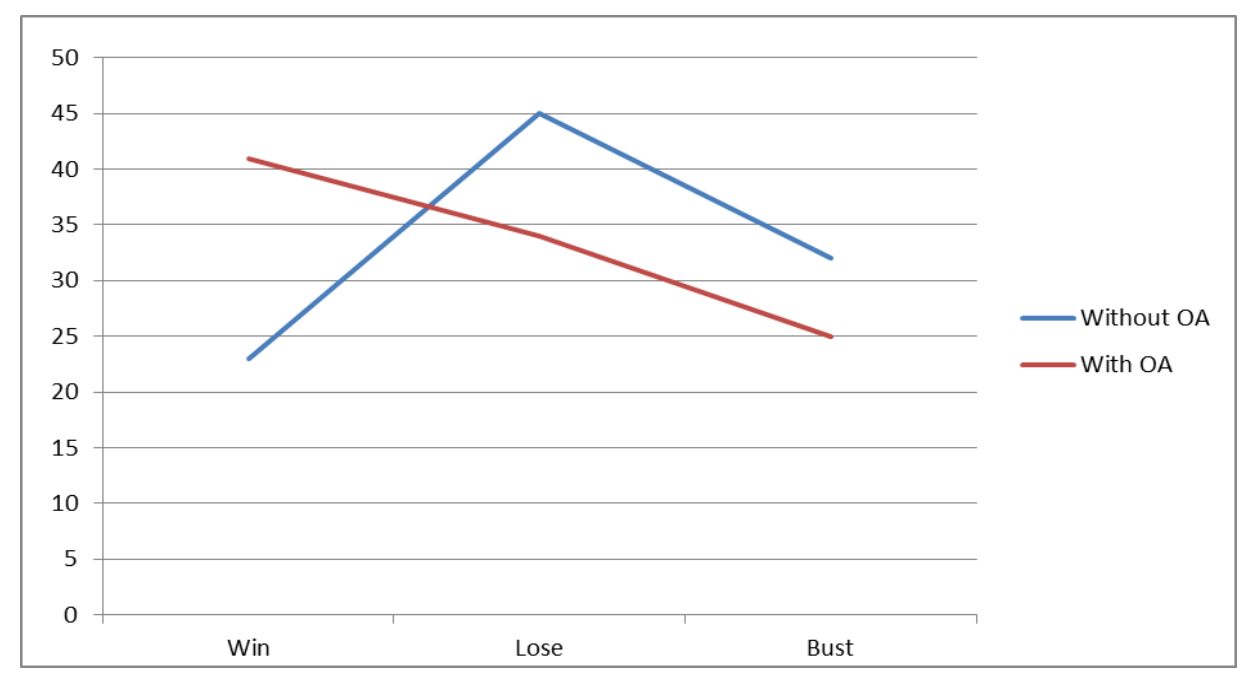

Fig 11: Score Comparative of Result Test

Figure 11 is a comparative use of optimization algorithms. The results obtained are the use of optimization algorithms affect the level of player AI win, with the possibility bust is also reduced. Through the optimization algorithm has 
improved the quality of AI. The development of quality AI make the game more challenging, thus spurring the user wishes to play. Furthermore, after the phase tested the program and then increasing user interest is measured by filling the questionnaire.

\subsubsection{Testing by User}

Traditional Card Game Rummy 21 is tested in Android device on smartphone and played by the user. In the Figure 12 and Figure 13 is the documentation of the application user.

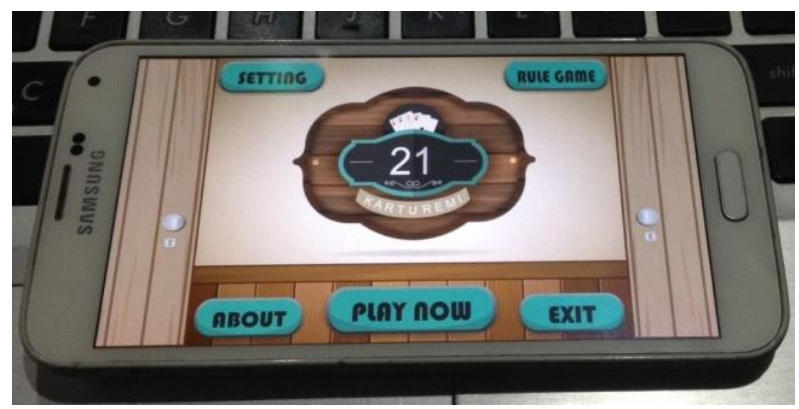

Fig 12: Testing Game in Android Device

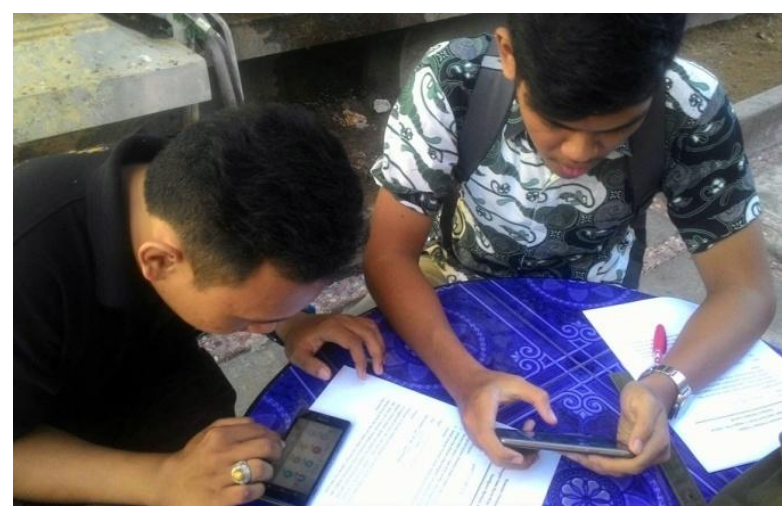

Fig 13: Testing Game by the User

Game Rummy 21 tested on android devices have gone well and the users who tested the application of this game is very excited and feel challenged by the features artificial intelligence to try to win the game.

The application is tested with fill out a questionnaire carried out by 25 users of either men or women at random. Tester of this application is that the user knows or not about the traditional card game Rummy 21. Tester is done tend to young people with vulnerable users age 17 to 25 years is keeping the traditional game that has not been forgotten. The results of the questionnaire after play the game Rummy 21 shown in Figure 13.

Table 2: Result of the Game Rummy 21 Tested

\begin{tabular}{|l|c|c|c|c|}
\hline \multirow{2}{*}{ Statement } & \multicolumn{4}{|c|}{ Percentage (\%) } \\
\cline { 2 - 5 } & $\begin{array}{c}\text { Need } \\
\text { Improve }\end{array}$ & Fair & Good & Excellent \\
\hline $\begin{array}{l}\text { Interesting of } \\
\text { application } \\
\text { display }\end{array}$ & 0 & 0 & 45 & 55 \\
\hline $\begin{array}{l}\text { Easy using the } \\
\text { application }\end{array}$ & 0 & 12,4 & 58,2 & 29,4 \\
\hline $\begin{array}{l}\text { Application } \\
\text { run well }\end{array}$ & 0 & 9,2 & 59,3 & 31,5 \\
\hline
\end{tabular}

\begin{tabular}{|l|l|l|l|l|}
\hline $\begin{array}{l}\text { Application is } \\
\text { helping to } \\
\text { know an } \\
\text { traditional } \\
\text { card games }\end{array}$ & 0 & 0 & 62,4 & 37,6 \\
\hline $\begin{array}{l}\text { Applications } \\
\text { is give the } \\
\text { challenge of } \\
\text { play the card } \\
\text { game }\end{array}$ & 0 & 15,6 & 61,1 & 23.3 \\
\hline
\end{tabular}

The users of the game Rummy 21 most gave a good opinion on this application. The users who tested this application were very enthusiastic to try played the game, and most have understood the game Rummy 21 . The most interesting part of the users is when get Ngerusak or Ngeliper, then automatically win the game. Ngadu and Ngertu can be a challenge for users as compete to get the greatest value of the cards against the computer AI.

\section{CONCLUSION}

This is thus the implementation of optimization algorithms on traditional card game Rummy 21. Features artificial intelligence (AI) used in computers have had success with the action chooses to take the card, or stay on the value of the card. The decision to add to the card at every step has been optimally carried out, taking into account the number of remaining players. Optimizing each step will give the expected results satisfactory end (optimum). This is evidenced through tested before use and after use optimization algorithms. The results obtained are AI winning rate increases and the risk of bust also declined.

Design Rummy 21 has run well on Android smartphones. AI has presented a challenge to the user in a single player game play. The presence of Rummy 21 Bali has preserved the traditional game by converting via media smartphone. Evidenced by the results of user testing which states, Rummy 21 helps to know the traditional game Bali. Rummy 21 also presents a challenge with AI features in it and the majority of users are interested in playing.

\section{ACKNOWLEDGEMENTS}

Thank you for Department of Information Technology Udayana University, for support and guidance on project designed from the beginning to the end.

\section{REFERENCES}

[1] Adi, P. and Darma Putra, I K.G. "Game Block Bakar with Android-Based uses the Method LCG and LFSR." Journal of MERPATI, Vol. 03, No 03, ISSN 2252-3006, December 2015.

[2] Andrew G. "Bridges Between Deterministic and Probabilistic Models for Binary Data", Statistical Methodology 7, 187-209, 2010.

[3] Darryl, C. "Enhancing Gameplay: Challenges for Artificial Intelligence in Digital Games." Journal DiGRA, Vol. 02, ISSN 2342-9666, 2014.

[4] Hapnes T. and Billy K. "Applications Games Capsah Banting with Applying Minimax Algorithm." Journal Informatika, Vol. 04, No 1, pp.12-27, June 2008.

[5] Kusumadewi. "Artificial Intelligence (Techniques and Applications)." Graha Ilmu, Yogyakarta, 2003. 
[6] Muhamad, D. "Artificial Intelligence." Journal SAINTIKOM, Vol. 05, No 02, pp. 185-197, 2008.

[7] Oka Sudana, A.A.K., Interview of "Traditional Card Game Rummy 21 Rules." Lecturers of Campus Information Technology, Udayana University Indonesia. (19 September 2015, At 13:30 pm)

[8] Petar Čisar. "Implementation of Immunological Algorithms in Solving Optimization Problems." Acta Polytechnica Hungarica, Vol. 11, No. 4, 2014.

[9] Reference for Balinese Traditional Games: www.dewatanews.com/2013/08/
[10] Reference for Optimized Algorithm: http://www.nagapena.web.id/2015/07/.

[11] Reference for Optimized Algorithm: news.mit.edu/2015/optimizing-optimization-algorithms0121

[12] Tjakra J., Arief S., and Daniel A. "Visual Design Rummy Cards for Soldiers Introduce Traditional Indonesian Biodiversity." Journal DKV Adiwarna, Vol. 01, No 02, 2013. 